Variações nos teores do C total e isotópico do solo após substituição do cerrado em sistemas agrícolas no Triângulo Mineiro Vania Rosolen, Thalita Mendes Resende, Elias Nascentes Borges, Cristiane Tumang Frare, Henrique Amorim Machado

\title{
VARIAÇÕES NOS TEORES DO C TOTAL E ISOTÓPICO DO SOLO APÓS SUBSTITUI- ÇÃO DO CERRADO EM SISTEMAS AGRÍCOLAS NO TRIÂNGULO MINEIRO
}

\section{Changes in the total and isotopic soil carbon after conversion from Cerrado to agricultural systems in the Triângulo Mineiro}

Vania Rosolen

Profa. Dra., Instituto de Geografia - Universidade Federal de Uberlândia vrosolen@ig.ufu.br

Thalita Mendes Resende Doutoranda no Programa de Pós Graduação em Geografia - UFU thalitamresende@yahoo.com.br

Elias Nascentes Borges Prof. Dr. do Instituto de Ciências Agrárias - UFU elias@ufu.br

Cristiane Tumang Frare Profa. Dra. da Universidade de Uberaba - UNIUBE cristiane.tumang@uniube.br

Henrique Amorim Machado Mestrando no Programa de Pós Graduação em Geografia - UFU henriquedageo@yahoo.com

Artigo recebido em 28/02/2012 e aceito para publicação em 13/04/2012

RESUMO: $\quad$ Os solos do Cerrado sofrem impactos resultantes da substituição da vegetação original em sistemas agrícolas traduzidos na forma de desequilíbrios nos estoques e natureza do carbono. A região do Triângulo Mineiro vem sendo intensamente desmatada por ser uma área pioneira de expansão do agronegócio e apresenta sérios problemas relacionados à erosão do solo. Esta pesquisa teve como objetivo avaliar as mudanças na quantidade (Ctotal) na natureza $\left(\delta^{13} \mathrm{C}\right)$ do carbono do solo após conversão do cerrado denso em áreas com diferentes usos agrícolas (pastagem, soja e rotação soja/milho), manejos (sistemas convencionais e plantio direto). Os resultados mostraram que as mudanças nos valores relacionados ao uso e manejo são determinados também pelas características texturais dos solos formados pela alteração de litotipos distintos. Dentre os diferentes usos e manejo, o maior enriquecimento da taxa de carbono foi determinado na área com soja/milho no sistema de plantio direto em solo argiloso e o maior empobrecimento em pastagens não manejadas em solos desenvolvidos da alteração do arenito das Formações Adamantina e Marília. Estes estudos são úteis para serem usados como indicadores de qualidade para a conservação ambiental.

Palavras-Chave: Cerrado, matéria orgânica do solo, carbono orgânico total, carbono isotópico, sistemas agropecuários. 
Variações nos teores do $\mathrm{C}$ total e isotópico do solo após substituição do cerrado em sistemas agrícolas no Triângulo Mineiro Vania Rosolen, Thalita Mendes Resende, Elias Nascentes Borges, Cristiane Tumang Frare, Henrique Amorim Machado

ABSTRACT The Cerrado soils suffer impacts related to the conversion of the original vegetation in agricultural systems, e.g., in the imbalances of stocks and nature of carbon. The Triângulo Mineiro region has been deforested by supporting the expansion of agribusiness and presents serious problems related to soil erosion. This study aimed to assess changes in content (Ctotal) and in nature $(\delta 13 \mathrm{C})$ of soil organic carbon after conversion of cerrado in different agricultural uses (pasture, soybean and soybean / corn), management (tillage and no-tillage). The results showed that changes in the values related to the use and management are also determined by the textural characteristics of soils formed by the alteration of different rock types. Among the different uses and management, the greater enrichment of the carbon content was determined in the no-tillage soybean / corn in a clayey soil and the further impoverishment was determined in not managed pastures developed in sandy soils from sandstones of Adamantina and Marília Formations. These studies are useful for use as quality indicators for environmental conservation.

Keywords: Brazilian savannah, soil organic matter, total organic carbon, carbon isotope, agricultural systems.

\section{INTRODUÇÃO}

As características iniciais dos solos do Cerrado se modificam pela conversão do uso da terra e manejo. Originalmente a área recoberta com Cerrado ocupava cerca de 2 milhões de $\mathrm{Km}^{2}$ sendo que, a partir da década de 1930, os projetos de integração nacional tornou esta área prioritária para a expansão da fronteira agrícola e, a partir da década de 1970, um modelo de modernização da agricultura brasileira, pautada nos usos intensivos do solo, máquinas e insumos agrícolas (WANIEZ, 1992; BALBINO et al., 2002; BROSSARD; LÓPES-HERNÁNDEZ, 2005). Imensas áreas de vegetação original foram desmatadas por corte e queima e substituídas por monoculturas de grãos (soja e milho, principalmente), algodão, pastagens manejadas associadas com pastagens degradadas (naturais), entre outros. De acordo com Lopes (1996) metade do Cerrado é composto por terras potencialmente aráveis e dois terços podem ser incorporados como sistemas agrícolas.

O Cerrado se desenvolve em condições de clima tropical com 2 períodos de contrastes pluviométricos caracterizados em período seco e chuvoso.Aprecipitação média anual podevariarde 400 $\mathrm{mm}$ a $2.200 \mathrm{~mm}$ (SILVA; ASSAD; EVANGELISTA, 2008) concentrada entre os meses de outubro a abril. Os outros meses caracterizam o período seco nos quais praticamente não há chuvas. As temperaturas aumentam no sentido sul-norte do Bioma com variações médias das temperaturas máximas anuais entre 24 e $33^{\circ} \mathrm{C}$ e das temperaturas mínimas de 14 a $23^{\circ} \mathrm{C}$ (SILVA; ASSAD; EVANGELISTA, 2008). Os solos tropicais lateríticos representados por Latossolos, Neossolos Quartzarênicos e Argissolos recobrem aproximadamente $75 \%$ do Bioma (REATTO et al., 2008). São solos ácidos (pH entre 4,5-5,5), lixiviados, dessaturados, alta concentração de Al trocável e constituído por argila de baixa atividade (LAC). A composição mineralógica comum associa caolinita, gibbsita, hematita e goethita e quartzo residual (MACEDO; BRYANT, 1987) cujos teores variam de acordo com a litologia e posição topográfica (VOLKOFF, 1985; CURI; FRANZMEIER, 1984). Os solos do Cerrado são extremamente frágeis e a erosão superficial ou em sulcos se constituem em um dos maiores problemas ambientais. Se os Latossolos do Cerrado possuem microestrutura muito estável, a macroestrutura é frágil e pouco desenvolvida e, quando presentes, são subangulares à grumosa (BALBINO et al., 2002).

Em virtude da substituição da vegetação original em sistemas agrícolas, atualmente apenas $51,54 \%$ ou $1.051 .182 \mathrm{~km}^{2}$ compõem as áreas de remanescentes da vegetação original e, apenas 5,2\% da área total está protegida sob a forma de alguma política de conservação (MMA, 2010). A taxa anual de conversão do uso do solo entre os anos de 1999 e 2005 foi de 1,55\% (JEPSON, 2005). Dentre as várias modificações ambientais relacionadas ao 
Variações nos teores do C total e isotópico do solo após substituição do cerrado em sistemas agrícolas no Triângulo Mineiro Vania Rosolen, Thalita Mendes Resende, Elias Nascentes Borges, Cristiane Tumang Frare, Henrique Amorim Machado

desmatamento do Cerrado destacam-se a erosão e os desequilíbrios nos estoques de carbono (KLINK; MACHADO, 2005), a substituição das fontes de carbono para o solo (BALESDENT et al., 2000) e a redução do carbono ligado à biomassa e a matéria orgânica do solo (LAL, 2003; EGOH et al., 2009).

O cenário atual de conversão da vegetação original em sistemas agrícolas reflete em grande parte a expansão agrícola pautada na produção em larga escala de monoculturas nas formas de plantio convencional e, após 1990, a substituição parcial desta prática de manejo para sistema de plantio direto. Estima-se que hoje a área cultivada por este sistema no Cerrado seja de aproximadamente 8 milhões de hectares (JANTÁLIA et al., 2007). Estudos focando aumento ou diminuição da matéria orgânica do solo como resultado desta prática de manejo em relação ao Cerrado nativo apontaram para a conservação do carbono do solo quanto para diferenças pouco expressivas uma vez que fatores como a textura e mineralogia interferiram diretamente no acúmulo de carbono (SILVA; LEMAINSKI; RESCK, 1994; FREITAS et al., 2000; LAL, 2002; SILVA et al., 2004; JANTÁLIA et al., 2007; MARCHÃO et al., 2009).

Quando não manejados adequadamente, os sistemas agrícolas e as pastagens degradadas liberam $\mathrm{C}$ e $\mathrm{N}$ para a atmosfera em função da rápida mineralização, cujo estoque inicial não é alcançado devido à diminuição da biomassa aérea e a não reacumulação da matéria orgânica no solo. A dinâmica de perda e não reposição do $\mathrm{C}$ e $\mathrm{N}$ estocados originalmente no solo pode ser considerada como um dos prováveis fatores de degradação dos solos e da biodiversidade no bioma cerrado. $\mathrm{O}$ declínio do $\mathrm{C}$ e $\mathrm{N}$ dos solos em resposta à conversão de uso foi documentado em várias pesquisas em diferentes ecossistemas tropicais (RESCK et al., 2000; CERRI et al., 2006; CARVALHO et al., 2009). Por outro lado, outros trabalhos relataram que além do manejo, características como textura e mineralogia interferem diretamente no acúmulo de carbono no solo (FREITAS et al., 2000; BAYER et al., 2006; MARCHÃO et al., 2009).

O objetivo deste artigo é avaliar as mudanças na natureza $\left(\delta^{13} \mathrm{C}\right)$ e quantidade do carbono orgânico total (COT) do solo após conversão da vegetação de cerrado denso (Cerradão) em áreas com diferentes usos (pastagem, soja e rotação soja/milho), manejos (sistemas convencionais e plantio direto) e/ou características texturais dos solos como produto da alteração de diferentes litotipos visando comparar a influência desses fatores na dinâmica do carbono orgânico do solo.

\section{MATERIAIS E MÉTODOS}

\section{Área de Pesquisa e Coleta das amostras no} campo

As amostras de solo foram coletadas região do Triângulo Mineiro, oeste de Minas Gerais, Brasil (Figura 1). A região, recoberta originalmente pela vegetação de Cerrado, vem sendo intensamente desmatada, desde a década de 1970, por ser uma área pioneira de expansão do agronegócio no Bioma Cerrado (WANIEZ, 1992; BALBINO et al., 2002; BROSSARD; LÓPEZ-HERNÁNDEZ, 2005).

Baseando-se nas diferentes categorias de uso, manejo e/ou textura do solo pautada em mudança de litotipos, foram escolhidos 12 pontos para coleta das amostras de solos (Figura 1). O ponto de coleta 1 corresponde a uma área de remanescente de cerrado arbóreo denso (cerradão) sobre latossolo arenoargiloso desenvolvido da alteração de sedimentos arenosos continentais depositados em clima semiárido da Formação Marília (Grupo Bauru). Esta formação recobre os basaltos da Formação Serra Geral. Os pontos 2, 4, 6 e 8 referem-se a áreas de pastagens manejadas sobre, respectivamente, latossolo vermelho argiloso desenvolvido da alteração do Basalto da Formação Serra Geral (Cretáceo), latossolo argilo-arenoso desenvolvido da alteração da cobertura detrito-laterítica que corresponde a sedimentos finos depositados no final do Terciário em ambiente tropical úmido sobre o sedimento da Formação Marília, latossolo arenoso desenvolvido da alteração de arenitos da Formação Adamantina (Grupo Baurú, do Eocretáceo) constituídos por sedimentos continentais de ambientes árido e semiárido depositados sobre os basaltos da Formação Serra Geral e, finalmente, latossolo areno-argiloso 
Variações nos teores do C total e isotópico do solo após substituição do cerrado em sistemas agrícolas no Triângulo Mineiro Vania Rosolen, Thalita Mendes Resende, Elias Nascentes Borges, Cristiane Tumang Frare, Henrique Amorim Machado

Figura 1. Localização dos pontos de coleta das amostras de solo no Triângulo Mineiro/MG

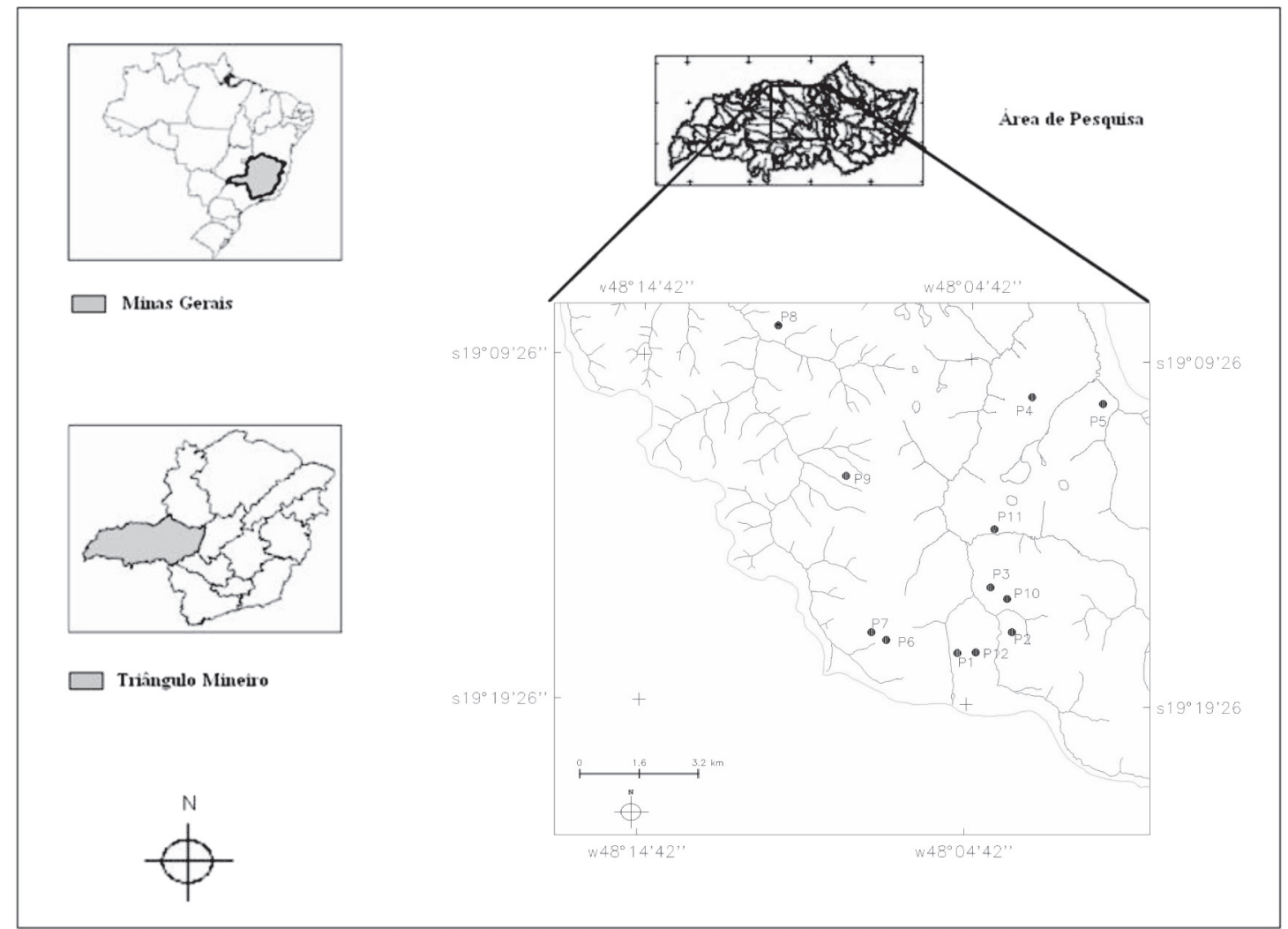

Org. dos autores.

desenvolvido da alteração dos sedimentos da Formação Marília.

Os pontos de 3, 5, 7 e 9 tratam-se de áreas de pastagens não manejadas em, respectivamente, latossolo vermelho argiloso formado a partir da alteração de basalto, latossolo argilo-arenoso formado da alteração da cobertura detrito-laterítica, latossolo arenoso formado da alteração dos sedimentos da Formação Adamantina e latossolo areno-argiloso formado da alteração dos sedimentos da Formação Marília.

$\mathrm{O}$ ponto 10 trata-se de uma área com plantio de soja sob sistema convencional em área de latossolo vermelho argiloso desenvolvido em basalto. $O$ ponto 11 refere-se a uma área com plantio de soja rotação com milho em sistema de plantio direto sobre latossolo argilo-arenoso em cobertura detrito-laterítica, enquanto que o ponto 12 trata-se de uma área com plantio de soja rotação com milho em sistema de plantio direto sobre latossolo argiloso em basalto.

As amostras foram coletadas em trincheiras na profundidade $0-30 \mathrm{~cm}$ em triplicata como sugerido por Bernoux et al. (2002). A avaliação textural foi feita em campo de acordo com o protocolo de descrição de solo no campo.

Após a coleta, as amostras foram secadas em ambiente seco e ventilado. Em seguida foram destorroadas, homogeneizadas e passadas em peneira com abertura de malha de $2 \mathrm{~mm}$ para obter a fração terra fina.

Determinação do carbono orgânico total (COT) e da natureza do carbono $\left(d^{13} \mathrm{C}\right)$

Para determinação da concentração de carbono orgânico (COT) e natureza do carbono $\left({ }^{13} \mathrm{C}\right)$, 
Variações nos teores do C total e isotópico do solo após substituição do cerrado em sistemas agrícolas no Triângulo Mineiro Vania Rosolen, Thalita Mendes Resende, Elias Nascentes Borges, Cristiane Tumang Frare, Henrique Amorim Machado

as amostras de solo foram secadas a $50^{\circ} \mathrm{C}$ até peso constante. Raízes e outros resíduos vegetais foram removidos por catação e peneiramento. Qualquer material vegetal remanescente foi removido por flotação em $\mathrm{HCl} 0,01 \mathrm{~mol} \mathrm{~L}^{-1} \mathrm{e}$, posteriormente, peneiramento em malha de $210 \mathrm{~mm}$. O carbono isotópico $\left({ }^{13} \mathrm{C}\right)$ e o carbono orgânico total (COT) foram determinados usando um analisador Carlo Erba Analyser CHN-1110, anexado a um espectrômetro de massa Optima Thermo Finnigan, Plus Delta. As incertezas analíticas variaram em média $0,3-0,5 \%$. As análises foram feitas em triplicatas e os teores de carbono orgânico total foram expressos em gramas por quilo $\left(\mathrm{g} \mathrm{Kg}^{-1}\right)$ e do carbono isotópico em $\delta^{13} \mathrm{C}$ $\%$. O padrão usado na terminação do $\delta^{13} \mathrm{C}$ é o $\mathrm{PDB}$, um carbonato (Belemnita americana) da formação Pee Dee da Carolina do Sul (EUA). A relação molar ${ }^{13} \mathrm{C} /{ }^{12} \mathrm{C}$ neste padrão é constante em 0,01124 e é usado para cálculo do desvio $(\delta)$ da relação ${ }^{13} \mathrm{C} /{ }^{12} \mathrm{C}$ em uma amostra natural (FARQUHAR; EHLERINGER; HUBICK, 1989). Por resultarem em valores muito baixos, convencionou-se a expressá-los em partes por mil (\%o). A composição isotópica média do ${ }^{13} \mathrm{C}$ da matéria orgânica do solo reflete a vegetação ou sucessão de vegetações que a produziu (DEINES, 1980).

\section{RESULTADOS E DISCUSSÕES}

Mudanças no uso e manejo das terras alteram a dinâmica e a natureza do carbono orgânico total (COT). Outros atributos inerentes ao solo, como a textura, são determinantes nas variações do teor de carbono, principalmente nas camadas superficiais dos solos (FELLER et al., 1991). Nos pontos de amostragens desta pesquisa o teor e a natureza do carbono variaram em função dos diferentes usos e tipos de manejos, bem como em relação à textura do solo, produto da pedogênese de litologias distintas (Tabela 1).

No Latossolo areno-argiloso sob vegetação original de cerrado arbóreo denso, considerada como amostra de referência para cálculo das determinações do teor e natureza do carbono no ambiente de Cerrado, na profundidade entre $0-30 \mathrm{~cm}$, o teor médio de carbono (COT) foi de $17,5 \mathrm{~g} \mathrm{Kg}^{-1}$, com valores mínimo e máximo variando entre 15,0 e $20,0 \mathrm{~g} \mathrm{Kg}^{-1}$.

Nos solos recobertos com pastagem não maneja (Pontos 3, 5, 7 e 9) os teores médios de $\mathrm{C}$ variaram de 5,3 a 20,8 $\mathrm{g} \mathrm{Kg}^{-1}$, com reflexo evidente da litologia e textura do solo. A pastagem não manejada sobre latossolo Vermelho argiloso (Ponto 3), proveniente da alteração do basalto, apresentou teor médio de $\mathrm{C}$ de 20,8 $\mathrm{g} \mathrm{K} \mathrm{g}^{-1}$, enquanto que sobre Latossolos arenosos da Formação Adamantina (Ponto 7) foi determinado o menor teor de C, com média de $9,1 \mathrm{~g} \mathrm{Kg}^{-1}$ e sobre latossolo areno-argiloso da Formação Marília (Ponto 9) foi determinado valor médio de $5,3 \mathrm{~g} \mathrm{Kg}^{-1}$. No Ponto 9, apesar de apresentar textura mais argilosa, a pastagem estabelecida em gramíneas do cerrado é pouco densa e o solo permanece descoberto.

No caso do Ponto 7, a gramínea, embora pouco densa, era composta por braquiária. Nos latossolos argilo-arenosos desenvolvidos a partir das Coberturas detrito-lateríticas (Ponto 5), o teor médio de $\mathrm{C}$ nas pastagens convencionais foi de $11,3 \mathrm{~g} \mathrm{Kg}^{-1}$. Os resultados indicam que para um mesmo uso e prática de manejo, o teor de carbono variou e apresentou estreita relação com as características mineralógicas e texturais. $\mathrm{O}$ menor teor médio obtido no solo arenoso pode ser explicado pelas características intrínsecas ao próprio solo visualmente observáveis no campo, como o baixo desenvolvimento de estrutura, grande quantidade de grãos de quartzo lavados e soltos na superfície, inúmeras ravinas de profundidade centimétrica em posições da vertente com solo descoberto. A associação de pastagens não manejadas tecnicamente com solos de baixa fertilidade natural e sem estruturação física resulta em baixa produção de biomassa aérea e radicular, condições estas que resultam em redução do teor de carbono do solo, conforme verificado também por Silva et al., 2004.

Em ambientes do Cerrado, a baixa produtividade das pastagens naturais, ou seja, aquelas formadas após o corte e a queima da vegetação de Cerrado que, em virtude de limitações climáticas e edáficassãodebaixaqualidadeequantidade, estimulou a introdução de pastagens com espécies vegetais africanas (Brachiária, Panicum e Andropogon) mais produtivas e com maior potencial de aumento do estoque de carbono no solo (SAVIDAN et al., 1985; BALBINO et al., 2002; CERRI et al., 2003; 
Variações nos teores do C total e isotópico do solo após substituição do cerrado em sistemas agrícolas no Triângulo Mineiro Vania Rosolen, Thalita Mendes Resende, Elias Nascentes Borges, Cristiane Tumang Frare, Henrique Amorim Machado

Tabela 1. Teor e natureza do carbono orgânico sob diferentes usos, sistemas de manejo e tipo de solo no Triângulo Mineiro / MG.

\begin{tabular}{|c|c|c|c|c|}
\hline $\begin{array}{c}\text { Ponto } \\
\text { (identificação) }\end{array}$ & Uso / Manejo & Solo / Litologia & $\begin{array}{l}\delta^{13} \mathbf{C} \\
(\% 0)\end{array}$ & $\begin{array}{l}\mathrm{COT}^{* *} \\
\left(\mathrm{~g} \mathrm{Kg}^{-1}\right)\end{array}$ \\
\hline $\mathrm{P} 1.1$ & \multirow{4}{*}{ Cerrado } & \multirow{4}{*}{$\begin{array}{l}\text { Latossolo areno-argiloso/Formação } \\
\text { Marília }\end{array}$} & $-26,08$ & 17,4 \\
\hline $\mathrm{P} 1.2$ & & & $-26,18$ & 20,1 \\
\hline P1.3 & & & $-26,33$ & 15,0 \\
\hline Média & & & $-26,20$ & 17,5 \\
\hline P2.1 & \multirow{4}{*}{ Pastagem manejada } & \multirow{4}{*}{ Latossolo vermelho argiloso/basalto } & $-18,28$ & 17,5 \\
\hline P2.2 & & & $-17,59$ & 18,2 \\
\hline P2.3 & & & $-17,78$ & 17,0 \\
\hline Média & & & $-17,58$ & 17,6 \\
\hline P3.1 & \multirow{4}{*}{$\begin{array}{l}\text { Pastagem } \\
\text { não manejada }\end{array}$} & \multirow{4}{*}{ Latossolo vermelho argiloso/basalto } & $-17,36$ & 21,2 \\
\hline P3.2 & & & $-17,61$ & 21,2 \\
\hline P3.3 & & & $-16,14$ & 20,0 \\
\hline Média & & & $-17,04$ & 20,8 \\
\hline P4.1 & \multirow{4}{*}{ Pastagem manejada } & \multirow{4}{*}{$\begin{array}{l}\text { Latossolo argilo-arenoso/ cobertura } \\
\text { detrito-laterítica }\end{array}$} & $-17,00$ & 23,1 \\
\hline P4.2 & & & $-16,60$ & 28,3 \\
\hline P4.3 & & & $-17,17$ & 29,1 \\
\hline Média & & & $-16,92$ & 26,8 \\
\hline P5.1 & \multirow{4}{*}{$\begin{array}{l}\text { Pastagem } \\
\text { não manejada }\end{array}$} & \multirow{4}{*}{$\begin{array}{l}\text { Latossolo argilo-arenoso/ cobertura } \\
\text { detrito-laterítica }\end{array}$} & $-17,67$ & 10,4 \\
\hline P5.2 & & & $-18,70$ & 10,5 \\
\hline P5.3 & & & $-18,00$ & 12,9 \\
\hline Média & & & $-18,12$ & 11,3 \\
\hline P6.1 & \multirow{4}{*}{ Pastagem manejada } & \multirow{4}{*}{$\begin{array}{c}\text { Latossolo arenoso/ arenito } \\
\text { Adamantina }\end{array}$} & $-14,98$ & 13,5 \\
\hline P6.2 & & & $-15,94$ & 15,7 \\
\hline P6.3 & & & $-14,86$ & 14,8 \\
\hline Média & & & $-15,26$ & 14,7 \\
\hline P7.1 & \multirow{4}{*}{$\begin{array}{c}\text { Pastagem } \\
\text { não manejada }\end{array}$} & \multirow{4}{*}{$\begin{array}{c}\text { Latossolo Arenoso/ Arenito } \\
\text { Adamantina }\end{array}$} & $-16,62$ & 8,5 \\
\hline P7.2 & & & $-18,18$ & 10,1 \\
\hline P7.3 & & & $-17,16$ & 8,6 \\
\hline Média & & & $-17,32$ & 9,1 \\
\hline P8.1 & \multirow{4}{*}{ Pastagem manejada } & \multirow{4}{*}{$\begin{array}{l}\text { Latossolo areno-argiloso/Formação } \\
\text { Marília }\end{array}$} & $-13,19$ & 8,0 \\
\hline P8.2 & & & $-13,26$ & 8,6 \\
\hline P8.3 & & & $-13,12$ & 10,9 \\
\hline Média & & & $-13,42$ & 9,1 \\
\hline P9.1 & \multirow{4}{*}{$\begin{array}{l}\text { Pastagem } \\
\text { não manejada }\end{array}$} & \multirow{4}{*}{$\begin{array}{l}\text { Latossolo areno-argiloso/Formação } \\
\text { Marília }\end{array}$} & $-14,27$ & 5,4 \\
\hline P9.2 & & & $-14,17$ & 5,1 \\
\hline P9.3 & & & $-13,66$ & 5,5 \\
\hline Média & & & $-14,03$ & 5,3 \\
\hline P10.1 & \multirow{4}{*}{ Soja convencional } & \multirow{4}{*}{ Latossolo vermelho argiloso/basalto } & $-19,92$ & 22,0 \\
\hline P10.2 & & & $-19,65$ & 22,3 \\
\hline P10.3 & & & $-20,01$ & 21,5 \\
\hline Média & & & $-19,86$ & 21,9 \\
\hline P11.1 & \multirow{4}{*}{ Milho/Soja PD* } & \multirow{4}{*}{$\begin{array}{l}\text { Latossolo argilo-arenoso/ cobertura } \\
\text { detrito-laterítica }\end{array}$} & $-21,22$ & 15,2 \\
\hline P11.2 & & & $-21,08$ & 15,0 \\
\hline P11.3 & & & $-21,41$ & 14,1 \\
\hline Média & & & $-21,24$ & 14,8 \\
\hline P12.1 & & & $-20,54$ & 22,8 \\
\hline $\mathrm{P} 12.2$ & Milho/Cais DD & & $-16,66$ & 23,6 \\
\hline $\mathrm{P} 12.3$ & Milho/soja PD & Latossolo/ basalto & $-17,43$ & 20,6 \\
\hline Média & & & $-18,21$ & 22,3 \\
\hline
\end{tabular}

* PD - Plantio Direto; **COT - Carbono Orgânico Total. Org. dos autores. 
Variações nos teores do C total e isotópico do solo após substituição do cerrado em sistemas agrícolas no Triângulo Mineiro Vania Rosolen, Thalita Mendes Resende, Elias Nascentes Borges, Cristiane Tumang Frare, Henrique Amorim Machado

MARCHÃO et al., 2009). Quando não manejadas adequadamente, as pastagens do Cerrado formam uma cobertura vegetal descontínua que expõe a superfície do solo. Nestes casos, especialmente quando se trata de solos arenosos, há perceptível perda da fase argilosa e aumento relativo da fração areia na forma de grãos de quartzo lavados e soltos.

Nos solos sob pastagem manejada (Pontos 2, 4, 6 e 8) o teor de C variou entre $9,1 \mathrm{~g} \mathrm{Kg}^{-1}$ e $26,8 \mathrm{~g} \mathrm{Kg}^{-1}$ e não apresentou relação estreita com textura do solo. Porém, no solo argiloso de basalto (Ponto 2) e no solo argilo-arenoso da cobertura detrito-laterítica (Ponto 4), os teores obtidos foram os maiores, com 17,6 g $\mathrm{Kg}^{-1}$ e $26,8 \mathrm{~g} \mathrm{Kg}^{-1}$, respectivamente. Comparando os resultados de $\mathrm{C}$ da pastagem manejada (Pontos 2, 4, 6 e 8) com os teores determinados nos solos com pastagem não manejada (Pontos 3, 5, 7 e 9), observa que o aumento na quantidade de carbono ocorreu nos solos com textura mais arenosa (Pontos 4, 6 e 8). A incorporação e o aumento do teor de $\mathrm{C}$ por meio do plantio da pastagem e do manejo tanto das adubações como da taxa de lotação animal foi mais eficiente que a textura nos solos que originalmente possuiam menor teor de matéria orgânica. Ambientes originalmente pobres em $\mathrm{C}$ pode resultar em condições menos favoráveis a mineralização quando comparados com solos iniciais ricos em $\mathrm{C}$ e a introdução de um sistema de manejo que recobre o solo, como as pastagens, pode elevar quantitativamente os estoques deste elemento (MORAES, 1991; FERNANDES et al., 2007).

Comparando uma área cultivada com soja em plantio convencional em solo argiloso de basalto com duas outras áreas de consórcio de soja/milho em plantio direto, uma sobre solo argilo-arenoso da cobertura detrito-laterítica e outra em solo argiloso de basalto, foram determinados teores médios de 21,9 $\mathrm{g} \mathrm{Kg}^{-1}, 14,8 \mathrm{~g} \mathrm{Kg}^{-1}$ e 22,3 $\mathrm{g} \mathrm{Kg}^{-1}$, respectivamente. Os resultados apontaram uma tendência de maior aporte de carbono estar associado a condição de solo argiloso e a técnica de manejo empregado.

Percebe-se pela tabela 1 que a gestão dos sistemas agrícolas pode resultar em aumento ou perdas de carbono do solo. Nos solos tropical característicos do cerrado, o manejo agrícola convencional contribui para elevar a perda de carbono do solo e aumentar o fluxo de $\mathrm{CO}_{2}$ para a atmosfera, enquanto que o plantio direto é uma prática de conservação que pode contribuir para a reposição e incoporação da matéria orgânica e mantenção da integridade da estrutura do solo, com redução de gases para a atmosfera (CERRI et al., 2006; CARVALHO et al., 2009). Porém, a resposta das diferentes técnicas de manejo traduzida em aumento das taxas de concentração de matéria orgânica podem apresentar mínimas variações na medida em que outros fatores limitantes como a textura, a mineralogia e a dificuldade de adição de C durante o período seco (FREITAS et al., 2000; ROSCOE; BUURMAN, 2003; BAYER et al., 2006).

Nesta pesquisa, o fato de todas as amostras de solo serem de composição laterítica constituído por argila de atividade baixa, a variação da textura foi relacionada ao material parental. Apesar de não ter sido calculado a significância do aumento ou diminuição das porcentagens de $\mathrm{C}$ dos solos amostrados, a tendência de empobrecimento de $\mathrm{C}$ esteve relacionado aos solos com teores mais elevados de areia, independente do uso e da técnica de manejo. Considerando que na região do Triângulo Mineiro predominam os solos provenientes das Formações sedimentares areníticas majoritariamente do Cretáceo Superior que recobriram as rochas basálticas da Formação Serra Geral na Bacia Sedimentar do Paraná, as fragilidades química e estrutural podem ser acentuadas em decorrência da diminuição e dificuldade de incorporação do $\mathrm{C}$ nas práticas agrícolas. Além da argila, a composição da caolinita, com elevado capeamento com óxido de ferro e alumínio, comuns aos solos lateríticos do Cerrado, interferem na decomposição da matéria orgânica e na redução da sua biodisponibilidade por meio das ligações de troca entre os íons férricos e as superfícies dos grupos funcionais da matéria orgânica (OADES et al., 1989; FELLER et al., 1991; BALESDENT et al., 2000; BAYER et al., 2006).

A avaliação das fontes para a incorporação da matéria orgânica nos solos foi possível por meio da análise isotópica $\delta^{13} \mathrm{C}$ (Tabela 1). Este tipo de determinação reflete a mudança da estrutura da vegetação de superfície e a incorporação de materiais orgânicos da cultura agrícola em detrimento da matéria orgânica natural do cerrado arbóreo, 
Variações nos teores do C total e isotópico do solo após substituição do cerrado em sistemas agrícolas no Triângulo Mineiro Vania Rosolen, Thalita Mendes Resende, Elias Nascentes Borges, Cristiane Tumang Frare, Henrique Amorim Machado

originalmente presente em toda a região amostrada. A vegetação do Cerrado brasileiro é composta predominantemente por espécies arbóreas $\mathrm{C}_{3} \mathrm{e}$ algumas gramíneas $\mathrm{C}_{4}$. $\mathrm{Na}$ área de estudo, a MOS da área recoberta por Cerrado apresentou valor médio de $\delta^{13} \mathrm{C}$ de $-26,08$. Os valores obtidos estão de acordo com aqueles determinados para as espécies arbóreas típicas do Cerrado com assinatura isotópica de -27,76\%. (HOFFMANN et al., 2005). O $\delta^{13} \mathrm{C}$ da matéria orgânica dos solos atualmente usados com pastagem convencional, pastagem manejada e com soja e soja/milho diferem daqueles determinados sob Cerrado e indicam clara tendência de alteração da decomposição e incorporação da MOS nas áreas convertidas. Houve mudança nítida de incorporação de plantas $\mathrm{C}_{4}$ originadas da gramínea no solo convertido em pastagem convencional e manejada que apresentou valores médios de $\delta^{13} \mathrm{C}$ entre $-14,03$ e $-18,12 \%$.

Nas áreas cultivadas com soja/milho em sistema plantio direto foi determinada assinatura isotópica que indica mistura de vegetação resultante da incorporação no solo de raízes e resíduos de soja $\left(\mathrm{C}_{3}\right)$ e milho $\left(\mathrm{C}_{4}\right)$. Os valores médios obtidos foram de $-18,21 \%$ e de $-21,24 \%$ no sistema milho/soja plantio direto e de $-19,86 \%$ no solo com soja convencional.

Os resultados obtidos mostraram que os desvios menos negativos relacionam-se as pastagens enquanto os mais negativos com as áreas de cultura soja e soja/milho, indicando tendência de substituição de incorporação da matéria orgânica de fontes mais recentes do que do cerrado. É necessário destacar que, embora tenha sido observada a tendência de mudança da assinatura isotópica em todas as áreas agrícolas em relação ao solo de fragmento de Cerrado, a avaliação mais precisa da mudança da fonte e estabilização da MOS seria mais precisa com o conhecimento dos dados históricos sobre as datas da alteração da vegetação (CERRI et al., 1985) uma vez que mudanças deste parâmetro são obtidas em longo prazo.

\section{CONCLUSÕES}

Manter o estoque de carbono orgânico nos solos tropicais convertidos em sistemas agrícolas é uma das condições essenciais para a conservação ambiental. Sob vegetação natural, os solos geralmente acumulam carbono orgânico e o desmatamento altera seu fluxo e natureza resultando em impactos nos corpos hídricos, biodiversidade e na qualidade dos solos. O desmatamento e o manejo inadequado interrompe a deposição da serrapilheira, aumenta a decomposição da matéria orgânica estocada no solo com perda da fertilidade química e física e aumenta as emissão de $\mathrm{CO}_{2}$ e outros gases para a atmosfera.

Os resultados desta pesquisa em solos originalmente recobertos por Cerrado mostraram transformações no teor e na natureza do carbono orgânico do solo em função da mudança de uso, manejo e textura, esta verificada no campo em função das diferentes litologias.

No entanto, comparações entre os teores de $\mathrm{C}$ nos solos sob pastagem não manejada e a tecnicamente manejada identificou que a aplicação de técnica de manejo isoladamente não foi suficiente para proporcionar aumento no teor deste elemento nos solos estudados. O teor de carbono, neste caso, variou e apresentou relação mais estreita com a textura do solo. Com relação à natureza do carbono $\left(\delta^{13} \mathrm{C}\right)$, nas áreas ocupadas por pastagens, seja com ou sem manejo, houve uma substituição do $\mathrm{C}$ da MOS de espécies $\mathrm{C}_{3}$ do Cerrado em $\mathrm{C}$ de gramíneas $\mathrm{C}_{4}$ quando comparadas com o solo de remanescente de Cerrado arbóreo.

Comparando as áreas cultivadas com soja em plantio convencional com soja/milho em sistema plantio direto houve uma tendência de maior concentração de carbono estar associada tanto a técnica de manejo quanto a presença do solo argiloso. A assinatura isotópica $\left(\delta^{13} \mathrm{C}\right)$ das áreas de plantio de soja revelou a presença de mistura de vegetação $\mathrm{C}_{3}$ (soja) e $\mathrm{C}_{4}$ (milho).

Os resultados obtidos neste artigo sugerem a dinâmica do C\% e C isotópico do solo quando os ecossistemas naturais são convertidos em sistemas agrícolas, porém, confirmaram a necessidade de considerar a diversidade dos solos e os usos e as técnicas de manejo dos solos agrícolas no Bioma Cerrado a fim de avaliar a dinâmica do carbono orgânico do solo e seus reflexos na conservação ambiental. 
Variações nos teores do C total e isotópico do solo após substituição do cerrado em sistemas agrícolas no Triângulo Mineiro Vania Rosolen, Thalita Mendes Resende, Elias Nascentes Borges, Cristiane Tumang Frare, Henrique Amorim Machado

\section{AGRADECIMENTOS}

Gostaríamos de agradecer a FAPEMIG ( Fundação de Amparo à Pesquisa do Estado de Minas Gerais) pelo financiamento do projeto de pesquisa (CRA - APQ - 01103-11) e a Capes peça concessão de bolsa de doutorado.

\section{REFERÊNCIAS}

BALBINO, L. C.; BROSSARD, M.; LEPRUN, J. C.; BRUAND, A. Mise en valeur des Ferralsols de la région du Cerrado (Brésil) et évolution de leurs propriétés physiques: une étude bibliographique. Étude et gestion des sols. Paris. v. 9, p. 83-104, 2002.

BALESDENT, J.; CHENU, C.; BALABANE, B. Relationship of soil organic matter dynamics to physical protection and tillage. Soil \& Tillage Research. New York. v.53, p.215-230, 2000.

BAYER, C.; MARTIN-NETO, L.; MIELNICZUK, J.; PAVINATO, A.; DIECKOW, J. Carbon sequestration in two Brazilian Cerrado soils under no-till. Soil \& Tillage Research. New York. v.86, p.237-245, 2006.

BERNOUX, M.; CARVALHO, M. C. S.; VOLKOFF, B.; CERRI, C. C. Brazil's soil carbon stocks. Soil Science Society American Journal. Madison. v. 66, p. 88-896, 2002.

BROSSARD, M.; LÓPES-HERNÁNDEZ, D. Des indicateurs d'évolution du milieu et des sols pour rendre durable l'usage des savanes d'Amérique du Sud. Natures Sciences Sociétés. Paris. v. 13, p. 266-278, 2005.

CARVAlHO, J. L. N.; CERRI, C. E. P.; FEIGL, B. J.; PICCOLO, M. C.; GODINHO, V. P.; HERPIN, U.; CERRI, C. C. Conversion of Cerrado into Agricultural Land in the South-Western Amazon: Carbon Stocks and Soil Fertility. Sci. Agric. Piracicaba. v. 66, n. 2, p. 233-241, 2009.
CERRI, C.; FELLER, C.; BALESDENT, J.; VICTORIA, R.; PLENECASSEGNE, A. Application du traçage isotopique naturel en ${ }^{13} \mathrm{C}$, à l'étude de la dynamique de la matière organique dans les sols. C.R. Acad. Sci. Paris. Paris. v. 11, n. 9, p. 423-428, 1985. CERRI, C. E. P.; COLEMAN, K.; JENKINSON, D. S.; BERNOUX, M.; VICTORIA, R.; CERRI, C. C. Modeling soil carbon from forest and pasture ecosystems of Amazon, Brazil. Soil Sci. Soc. Am. J. Madison. v. 67 , p. $1879-1887,2003$.

CERRI, C. C.; BERNOUX, M.; CERRI, C. E. P.; LAL, R. Challenges and Opportunities of Soil Carbon Sequestration in Latin América. In: LAL, R.; CERRI, C. C.; BERNOUX, M.; ETCHEVERS, J.; CERRI, E. Carbon Sequestration in Soils of Latin America. Haworth Press, 2006. p. 41-48.

CURI, N.; FRANZMEIER, D. P. Toposequence of oxisols from the Central Plateau of Brazil. Soil Science Society of America Journal. Madison. v. 48, n. 2, p. 341-346, 1984.

DEINES, P. The isotopic composition of reduced organic carbon. In: FRITZ, P.; FONTES, J. C. (Eds.). Handbook of Environmental Isotope Geochemistry, Amsterdam: Elsevier, v. 1, 1980. p.329-406.

EGOH, B.; REYERS, B.; ROUGET, M.; BODE, M.; RICHARDSON, D. M. Spatial congruence between biodiversity and ecosystem services in South Africa. Biol. Conserv. Boston. v. 142, p. 553-562, 2009.

FARQUHAR, G. D.; EHLERINGER, J. R.; HUBICK, K. T. Carbon isotope discrimination and photosynthesis. Annual Review of Plant Physiology and Molecular Biology. Palo Alto. v. 40, p. 503-537, 1989. 
Variações nos teores do C total e isotópico do solo após substituição do cerrado em sistemas agrícolas no Triângulo Mineiro Vania Rosolen, Thalita Mendes Resende, Elias Nascentes Borges, Cristiane Tumang Frare, Henrique Amorim Machado

FELLER, C.; FRITSCH, E.; POSS, R.; VALENTIN, C. Effects de la texture sur le stockage et la dynamique des matières organiquess quelques sols ferrugineux et ferralitiques (Afrique de l'Ouest, en particulier). Cah. ORSTOM, sér. Pédologie. Paris. v. 26, p. 25-36, 1991.

FERNANDES, F. A.; FERNANDES, A. H. B. M; CRISPIM, S. M. A. Biomassa microbiana e conteúdos de carbono e nitrogênio do solo em áreas de pastagem nativa sujeita à queimada,Pantanal Mato-Grossense - Corumbá, Boletim de Pesquisa e Desenvolvimento, Corumbá, n.73, 2007.

FREITAS, P. L.; BLANCANEAUX, P.; GAVINELLI, E.; LARRÉ-LARROUY, M. C.; FELLER, C. Nível e natureza do estoque orgânico de latossolos sob diferentes sistemas de uso e manejo. Pesq. Agropec. Bras. Campinas. v. 35, p. 157-170, 2000.

HOFFMANN, W. A.; FRANCO, A. C.; MOREIRA, M. Z.; HARIDASAN, M. Specific leaf area explains differences in leaf treats between congeneric savanna and forest trees. Functional Ecology. London. v. 19, p. 932-940, 2005.

JANTÁLIA, C. P.; RESCK, D. V. S.; ALVES, B. J. R.; ZOTARELLI, L.; URQUIAGA, S.; BODDEY, R. M. Tillage effect on $C$ stocks of a clayey Oxisol under a soybean-based crop rotation in the Brazilian Cerrado region. Soil \& Till. Res. New York. v. 95, p. 97-109, 2007.

JEPSON, W. A disappearing bioma? Reconsidering land-use cover change in the Brazilian savanna. The Geographical Journal. London. v. 171, n. 2, p. 99-111, 2005.

KLINK, C. A.; MACHADO, R. B. Conservation of brazilian cerrado. Conservation Biology. Washington. v. 19, p. 707-713, 2005.
LAL, R. Soil carbon dynamic in cropland and rangeland. Environmental Pollution. Amherst. v.116, p.353-362, 2002.

Global potential of carbon sequestration to mitigate the greenhouse effect. Critical Reviews in Plant Sciences, Boca Raton, v. 22, n. 2, p. 151-184, 2003.

LOPES, A. S. Soils under Cerrado: a success story in soil management. Better Crops Int. Saskatchewan. v. 10, p. 9-15, 1996.

MACEDO, J.; BRYANT, R. B. Morphology, Mineralogy, and Genesis of a hydrosequence of Oxisols in Brazil. Soil Science Society of America Journal. Madison. v. 51, p.690-698, 1987.

MARCHÃO, R. L.; BECQUER, T.; BRUNET, D.; BALBINO, L. C.; VILELA, L.; BROSSARD, M. Carbon and nitrogen stocks in a Brazilian clayey Oxisol: 13-year effects of integrated crop-livestock management systems. Soil Till. Res. New York. v. 103, p. 442-450, 2009.

MINISTÉRIO DO MEIO AMBIENTE - MMA. Projeto de Monitoramento do Desmatamento nos Biomas Brasileiros por Satélite. Disponível em: <www.mma. org.br/sitio/index.php?ido=conteudo.monta\&idEstrut ura $=201 \&$ idConteudo $=8448$ \&idMenu $=8982>$. Acesso em: Abril, 2010.

MORAES, J. F. L. Conteúdos de Carbono e Tipologia de Horizontes nos Solos da Bacia Amazônica. 1991. Tese de Doutorado - Centro de Energia Nuclear de Agricultura, Universidade de São Paulo. São Paulo, 1991.

OADES, J. M.; GILLMAN, G. P.; UEHARA, G. Interactions of soil organic matter and variable-charge 
Variações nos teores do C total e isotópico do solo após substituição do cerrado em sistemas agrícolas no Triângulo Mineiro Vania Rosolen, Thalita Mendes Resende, Elias Nascentes Borges, Cristiane Tumang Frare, Henrique Amorim Machado

clays. In: COLEMAN, D. C.; OADES, J. M.; UEHARA, G. (Eds.). Dynamics of Soil Organic Matter in Tropical Ecosystems. Honolulu: Hawaii Press, 1989. p.69-95.

REATTO, A.; CORREIA, J. R.; SPERA, S. T.; MARTINS, E. S. Solos do Bioma Cerrado: aspectos pedológicos. In: SANO, S. M.; ALMEIDA, S. P. D; RIBEIRO, J. F. (Eds.). Cerrado - Ecologia e Flora. Brasília, DF: Embrapa Informação Tecnológica, v.1, 2008. p.107-133.

RESCK, D. V. S; VASCONCELLOS, C. A; VILELA, L.; MACEDO, M. C. M. Impact of conversion of Brazilian Cerrados to cropland and pasture land on soil carbon pool and dynamics. In: LAL, R., KIMBLE, J. M.; STEWART, B. A. (Eds.), Global climate change and tropical ecosystems, Boca Raton, CRC Press, 2000, p. 169-196.

ROSCOE, R.; BUURMAN, P. Tillage effects on soil organic matter in density fractions of a Cerrado Oxisol. Soil \& Till. Res. New York. v. 104, p. 185-202, 2003.

SAVIDAN, Y.; JANK, J. DE; SOUZA, F. H. D.; BOOK, A. Preliminary evaluation of Panicum maximum germplasm in Brazil. In: INTERNATIONAL AGRONOMY RESEARCH PROGRAM. Proc. XVth. Int. Grassl. Congress, Kyoto, Japan, 1985. p.117-118.

SILVA, J. E. da.; LEMAINSKI, J.; RESCK, D. V. S. Perdas de matéria orgânica e suas relações com a capacidade de troca catiônica em solos da região de Cerrados do oeste Baiano. Rev. Bras. Cienc. Solo. Viçosa. v. 18, p. 541-547, 1994.

SILVA, J. E. da.; RESCK, D. V. S.; CORAZZA, E. J.; VIVALDI, L. Carbon storage in clayey Oxisol cultivated pastures in the "Cerrado" region, Brazil. Agriculture, Ecosystems and Environment. Zürich. v. 103, p. 357-363, 2004.
SILVA, F. A. M; ASSAD, E. D; EVANGELISTA, B. A. Caracterização climática do Bioma Cerrado. In: SANO, S. M.; ALMEIDA, S. P. D.; RIBEIRO, J. F. (Eds.), Cerrado-Ecologia e Flora. Brasília, DF, Embrapa Informação Tecnológica, v.1, 2008, p. 69-106.

VOLKOFF, B. Organisations régionales de la couverture pédologique du Brésil. Chronologie des différenciations. Cah. Orstom, sér. Pédologie. Paris. v. XXI, p. 225-236, 1985.

WANIEZ, P. Les Cerrados, un "espace frontière" brésilien. Montpellier: G.I.P. RECLUSORSTOM. Paris. 1992. 344 p. 
